\title{
Response to Selection for Increased
} Heat Tolerance in a Small Fish Species, With the Response Decreased by a Population Bottleneck

OPEN ACCESS

Edited by:

Robert Ptacnik,

Wasser Cluster Lunz, Austria

Reviewed by:

Mariano Ordano,

Fundación Miguel Lillo, Argentina

Shu-Jun Wei,

Beijing Academy of Agricultural and

Forestry Sciences, China

Etsuko Nonaka

Stockholm University, Sweden

*Correspondence:

Paul L. Klerks

klerks@louisiana.edu

Specialty section:

This article was submitted to

Population and Evolutionary

Dynamics,

a section of the journal

Frontiers in Ecology and Evolution

Received: 19 November 2018

Accepted: 27 June 2019

Published: 11 July 2019

Citation:

Klerks PL, Athrey GN and Leberg PL

(2019) Response to Selection for Increased Heat Tolerance in a Small

Fish Species, With the Response

Decreased by a Population

Bottleneck. Front. Ecol. Evol. 7:270

doi: 10.3389/fevo.2019.00270

\author{
Paul L. Klerks ${ }^{1 *}$, Giridhar N. Athrey ${ }^{1,2}$ and Paul L. Leberg ${ }^{1}$ \\ ${ }^{1}$ Department of Biology, University of Louisiana at Lafayette, Lafayette, LA, United States, ${ }^{2}$ Faculty of Ecology \& Evolutionary \\ Biology, Texas A\&M University, College Station, TX, United States
}

Many natural populations are likely to be impacted by increasing temperatures resulting from climate change. The selection pressures exerted by these impacts may allow some populations to adapt to the elevated temperatures - which could reduce climate change's impact. At present, there is limited evidence for such "evolutionary rescue." Moreover, the potential for adaptation may be reduced if populations have experienced population bottlenecks as an initial consequence of climate change or due to other human impacts. This study looked at the response to selection in laboratory populations subjected to selection for heat tolerance, in both normal and bottlenecked laboratory populations of the least killifish Heterandria formosa. The bottlenecked populations had undergone a single bottleneck and were found to have fewer microsatellite alleles and reduced genetic diversity. After four generations of selection, heat tolerance had increased-albeit by only $0.1^{\circ} \mathrm{C}$. The increased heat tolerance was more pronounced for normal populations than it was for those that had undergone a population bottleneck. These results show that some populations, under specific conditions, may be able to adapt to elevated water temperatures. However, this response may be too slow for species with a long generation time and further limited in populations that have undergone drastic reductions in population size. In addition, the observed potential for adaptation to physiological heat stress does not equate to evolutionary rescue from other stresses associated with climate change.

Keywords: climate change, genetic adaption, evolutionary rescue, water temperature, genetic variation

\section{INTRODUCTION}

Climate change is resulting in higher temperatures; combined land and ocean temperatures increased by about $0.85^{\circ} \mathrm{C}$ over the period $1880-2012$ (IPCC, 2014). As air temperature is the main determinant for changes in surface water temperature (Schmid et al., 2014), increased water temperatures in freshwater environments are expected and have indeed been reported for both lakes and rivers (Coats et al., 2006; Isaak et al., 2012; Dokulil, 2013; Kraemer et al., 2015; O’Reilly et al., 2015). Water temperature has many direct and indirect effects on aquatic organisms, including those resulting from physiological heat stress, changes in ice cover, water 
column stability, dissolved oxygen concentrations, nutrient dynamics, occurrence of harmful algal blooms, and timing of phytoplankton spring peaks (Dokulil, 2013). Consequently, elevated water temperatures are likely to have significant impacts on freshwater biota (Dokulil, 2013; IPCC, 2014). The present study is focusing on impacts on freshwater fish, because of their ecological and economical importance and because they are good sentinels for assessing broader impacts of climate change (Jeppesen et al., 2012; Izzo et al., 2016). A variety of effects have been noted for fishes in inland waters (as reviewed in Jeppesen et al., 2012; Comte et al., 2013; Dokulil, 2013; Lynch et al., 2016), including changes in species distributions and in species composition. While fish species extinctions to date seem mostly due to climate change having affected habitat and food availability (Cahill et al., 2013), increased temperature also appears to have resulted in extinctions (Beever et al., 2010; Sinervo et al., 2010; Cahill et al., 2013).

As many as $35 \%$ of all species may face extinction due to climate change (Thomas et al., 2004). However, case studies have shown that some natural populations can rapidly adapt to environmental changes (Klerks and Levinton, 1989; Oziolor et al., 2014; Reid et al., 2016; Campbell-Staton et al., 2017). Similarly, natural selection imposed by climate change could result in adaptations that could keep a population or species from going extinct, referred to as "evolutionary rescue" (Bell and Collins, 2008). Adaptation is now included with migration and extinction among the potential responses to climate change (Aitken et al., 2008), and the potential for an evolutionary response to climate change has been discussed (Carlson et al., 2014). Some adaptations to recent climate change have already been noted, including a change in timing of migration in salmonid fishes (Kovach et al., 2012) and in the timing of breeding in a red squirrel population (Réale et al., 2003).

While selective pressures resulting from elevated temperature or other climate changes can lead to an adaptation, it is not clear how likely such a response will be (Hoffmann and Blows, 1993; Carlson et al., 2014) or whether they will result in an evolutionary rescue (Grant, 2017). Consequently, experimental approaches are needed for quantifying the potential for such adaptations (Reusch and Wood, 2007; Bell and Collins, 2008). One approach involves determining the presence of heritable variation for traits favored in the altered environment (Weigensberg and Roff, 1996; Klerks et al., 2011; Tedeschi et al., 2016) and assessing the presence of negative genetic correlations that limit evolutionary responses (Sheldon et al., 2003; Garant et al., 2008). Another approach, and the one taken in the present study, is to assess the response to selection in laboratory populations (Roff, 1997). This approach has been widely used for assessing the response to selection for an increased tolerance to environmental stressors (Diamond et al., 1995; Xie and Klerks, 2003), including temperature (Bennett et al., 1990; Baer and Travis, 2000; Magiafoglou and Hoffmann, 2003; Kelly et al., 2016).

Severe reductions in population size (bottlenecks) and associated genetic drift may reduce the ability of populations to respond to selective pressures from environmental stressors (Bürger and Lynch, 1995; Skelly et al., 2007; Perrier et al., 2017). Doyle et al. (2011) found reduced heritability for heat tolerance for populations following a bottleneck. There is, however, little experimental evidence that such reductions in variation will affect adaptive responses to elevated temperature. Contrastingly, there is evidence of adaptation to local conditions in the face of population bottlenecks and high rates of genetic drift (Kavanagh et al., 2010; Perrier et al., 2017).

The present study consisted of a laboratory selection experiment with the least killifish Heterandria formosa, to determine its response to selection for an increased heat tolerance. We selected for an increased survival during exposure to lethal temperatures. Selection pressures for an increased heat tolerance may be most pronounced for species that can handle only a narrow range of temperatures and for species living close to their thermal maximum-as is evident from climate change effects on reef-building corals (McClanahan, 2004). As the threat of population extinction is strongest for populations that are already severely affected by heat or other anthropogenic stressors, we wanted to also assess the influence of population declines and associated loss of genetic variation on the response to selection. Selection for heat tolerance was therefore done for both populations that had and had not undergone a bottleneck (hereafter referred to as "bottlenecked" and "normal," respectively), to determine if the response to selection was reduced by the temporary decline in population size.

\section{MATERIALS AND METHODS}

Selection for heat tolerance was performed with laboratory populations of the least killifish Heterandria formosa-a small livebearer in the family Poecilliidae. This fish has a generation time that can be as short as 2-3 months (Leips and Travis, 1999; Xie and Klerks, 2004), making it well-suited for selection experiments. These fish are sexually dimorphic, females can store sperm, and females exhibit superfetation-where a single female carries multiple broods at different stages of development (Leips and Travis, 1999). Selection experiments were conducted with both normal and bottlenecked laboratory populations from each of three source populations (Figure 1). The three collection locations were a site near Lacassine National Wildlife Refuge $\left(30.014^{\circ} \mathrm{N}, 92.785^{\circ} \mathrm{W}\right)$, a site on Lake Martin-located near Lafayette $\left(30.331^{\circ} \mathrm{N}, 91.905^{\circ} \mathrm{W}\right)$, and a site on the Atchafalaya Basin near Henderson $\left(30.323^{\circ} \mathrm{N}, 91.788^{\circ} \mathrm{W}\right)$. Distances between the sites are: $105 \mathrm{~km}$ (Lacassine-Atchafalaya), $88 \mathrm{~km}$ (Lake Martin-Lacassine), and $16 \mathrm{~km}$ (Lake Martin-Atchafalaya). The normal laboratory populations were established using about 120 fish (60 males, 60 females) from each source population. Bottlenecked laboratory populations were initially established with one male and one virgin female (using first generation laboratory-born offspring from the normal populations). An extended power failure following a hurricane resulted in loss of males in initial bottleneck breeding pairs, requiring the introduction of a second male to each of the three founding females. Bottlenecked populations were allowed to grow to a population size of at least 120 individuals without any additional bottlenecks. For the starting generation (gen. 0) of the selection experiment, fish from a bottlenecked or normal laboratory population were randomly assigned to either a selection or control line (60 fish per line, numbers equally divided between the two sexes). At this point, the fish had been in the 


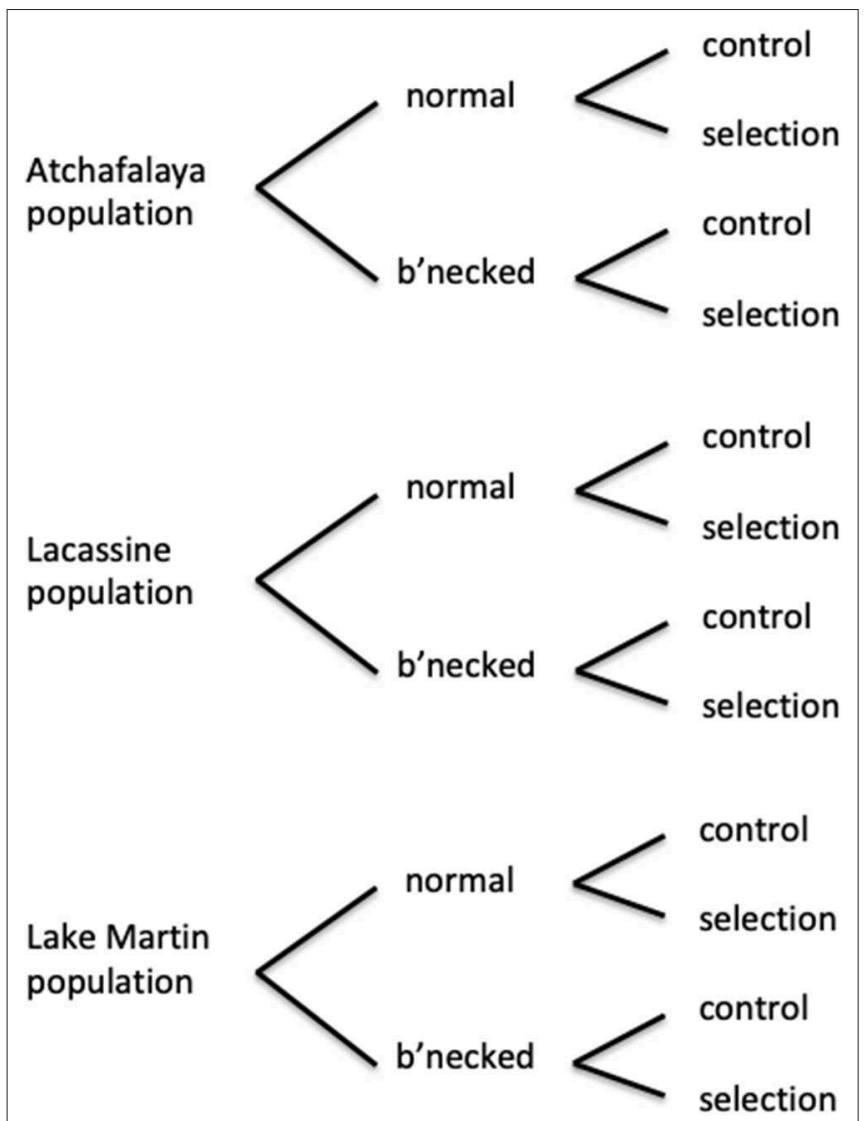

FIGURE 1 | Diagram of experimental design of selection experiments, with three source populations (each with a normal subpopulation maintained at about 120 individuals and a subpopulation passed through a single bottleneck with 2-3 individuals), and both a selection line and a control line for each of these subpopulations.

laboratory for about 13 months (three to four generations). The experimental design with three source populations, normal and bottlenecked lines, and control and selection lines for each, resulted in a total of 12 populations (Figure 1).

Fish were maintained in trays with recirculating local well water, in a greenhouse at the University of Louisiana's Ecology Center. Fish for each line were housed in a single shallow tray $(235 \mathrm{~cm} \mathrm{~L} \times 67 \mathrm{~cm} \mathrm{~W} \times 15 \mathrm{~cm} \mathrm{D})$ with $10 \mathrm{~cm}$ of water. Two trays were stacked vertically on a rack with about $55 \mathrm{~cm}$ space in between the trays, and shared the same recirculating water and filter tank $(244 \mathrm{~cm} \mathrm{~L} \times 61 \mathrm{~cm} \mathrm{~W} \times 61 \mathrm{~cm} \mathrm{D})$. A set of two trays was used for each pair of lines (control and selection), while location (top vs. bottom) was randomized for selection and control lines. Water temperatures in the greenhouse trays averaged approximately $30^{\circ} \mathrm{C}$ (range: $18-38^{\circ} \mathrm{C}$ ).

\section{Selection Process and Quantification of Heat Tolerance}

For each generation, the selection step and quantification of heat tolerance were combined. Offspring were raised in the greenhouse trays till almost mature, to ensure that no mating had occurred prior to the selection step, and then exposed to a gradually increasing water temperature in environmental chambers (I-36LL, Percival Scientific, Boone IA, USA). To quantify heat tolerance and select the most heat-tolerant individuals, equal numbers of juvenile fish $(8-11 \mathrm{~mm}$ standard length) were taken from both members of a pair of lines (selection/control) and placed inside the chamber in a single $30-\mathrm{L}$ tank with a mesh screen in the center separating the two groups. The aquaria were filled with water from the specific greenhouse tray system in which they had been raised. Gentle aeration was provided in the aquaria. The fish were allowed to acclimate for 7 days to the chamber conditions at a temperature of $28^{\circ} \mathrm{C}$. Fish were fed daily with fish flakes (TetraMin, Tetra, Blacksburg, VA, USA) or newly hatched brine shrimp. The chambers were programmed for a temperature increase of $2^{\circ} \mathrm{C} /$ day following this 7 -day acclimation. Fish survival and water temperature were checked daily; water temperatures were measured using a 4400 Series NIST Traceable Digital Thermometer (Alpha Technics, Oceanside CA, USA) with $0.01^{\circ} \mathrm{C}$ precision and $0.02^{\circ} \mathrm{C}$ accuracy. Once the water temperature reached about $38^{\circ} \mathrm{C}$, fish survival and water temperatures were checked at $2-3 \mathrm{~h}$ intervals (morefrequent checking was not feasible as opening of a chamber's door resulted in heat loss and drop in water temperature). Criterion for fish mortality was lack of movement of gill operculum; dead fish were removed when encountered. Once mortality exceeded $50 \%$, water temperatures were gradually cooled to about $28^{\circ} \mathrm{C}$ and the fish were returned to the greenhouse trays after about 4 days. Final mortality from an exposure was assessed 7 days after the end of the exposure. Delayed mortality from the heat exposures resulted in average heat-related mortality (including the initial $>50 \%$ ) of $73 \%$. Multiple exposures (4-15 exposures, totaling up to 431 fish) were conducted for each line for each generationin order to yield approximately 60 survivors per line (Online Resource 1 in Supplementary Material). For the selection lines, exposure survivors were used as parents for the next generation. For the control lines, fish were exposed in each generation to quantify their heat tolerance but parents for the next generation were chosen randomly among non-exposed juveniles-using the same total number and same sex ratio as were used for its paired selection line. On average, we had 26 males and 37 females as parents for the next generation. To distinguish fish from different generations, newborn offspring were separated from adults once weekly. Selection was continued for a total of 4 generations over a 4-year period.

\section{Microsatellite Analyses}

To assess the effects of the bottlenecking on genetic variation, 26 fish from generation 0 (i.e., prior to the start of the selection process) were taken from each of the 6 lines and subjected to genetic analysis. Analyses followed methods described earlier (Athrey et al., 2007), and used seven different nuclear microsatellite markers. Briefly, DNA was isolated from individual fish using the Gentra Puregene DNA isolation kit (Qiagen, Inc., CA, USA). Each microsatellite locus was amplified by polymerase chain reaction (PCR) in a $15 \mu$ l reaction volume running 35 amplification cycles, each with denaturation $\left(94^{\circ} \mathrm{C}\right)$, annealing $\left(53-60^{\circ} \mathrm{C}\right)$, and extension $\left(72^{\circ} \mathrm{C}\right)$ steps, and using a 
fluorescently labeled primer. Labeled PCR products were then analyzed on an ABI 3100 Genetic Analyzer (Applied Biosystems, Foster City, CA, USA), followed by peak calling and genotyping using the Genescan Genetic Analysis software (V3.1, Applied Biosystems). All population genetic estimates were calculated with the software program GDA (Lewis and Zaykin, 2001).

\section{Statistical Analyses}

Heterozygosity based on Hardy-Weinberg expectations $\left(\mathrm{H}_{\mathrm{HW}}\right)$, and Allelic richness $\left(A_{R}\right)$ were compared between normal and bottlenecked lines of a specific source population using a mixed model, with treatment (normal/bottlenecked) as a fixed effect and source and locus as random effects.

The response to selection for heat tolerance was analyzed using regression analysis. To reduce "noise" in heat tolerance due to environmental factors, and made possible by the fact that each selection line and its paired control line were exposed simultaneously, the response to selection was quantified as the difference in median temperature-at-death (TAD) between the two paired lines. For each individual exposure, the difference in median TAD (control vs. selection line fish) was calculated. Whether or not there was a response to selection was assessed on the basis of the difference in TAD between a pair of lines increasing with increasing generation number. In addition, regression analysis was used to assess the relationship between the cumulative selection response $(R)$ and the cumulative selection differential $(S)$. The selection differential is the difference between the population mean and the mean of the selected individuals. To calculate $S$, the proportion selected $(p)$ was converted to a selection intensity $(i)$. Selection intensity is a measure of the strength of selection, and is high if only the top-performing individuals are selected as parents for the next generation. Values of $p$ were converted to $i$ values using the "truncated normal distribution-large sample" table in Falconer and Mackay (1996) — assuming that TAD followed a normal distribution. Selection intensity was then converted to $S$ using the formula $S=i \times \delta$ (Falconer and Mackay, 1996), where $\delta$ is the phenotypic standard deviation in heat tolerance among the fish (we used $\delta$ averaged over all exposures and all lines). There was no evidence of this standard deviation differing between normal and bottlenecked selection lines $\left(F_{(1,22)}=0.019, p=\right.$ 0.892 in ANOVA). For regressions on both generation number and cumulative selection differential, intercepts were set at zero as the generation-zero individuals from the control and selection lines came from the same population (these became separate lines only after the first round of selection).

\section{RESULTS}

\section{Effects of Population Bottleneck on Genetic Variation}

For the seven microsatellite loci employed in this study, the number of alleles ranged from three to seven (Online Resource 2 in Supplementary Material). The bottlenecking resulted in a significant reduction in allelic richness $\left[F_{(1,32)}=13.80, p<\right.$ 0.001 ]. Least square means estimates were 4.62 (with a SE of 0.490 ) alleles per locus for the normal lines, vs. $4.0 \pm 0.490$ for the bottlenecked lines. The losses were limited to four of the seven loci, with one to three alleles being lost per locus. The three source populations did not differ significantly in $A_{\mathrm{R}}$ (Wald $p=0.547$ ).

Among the seven loci studied, $\mathrm{H}_{\mathrm{HW}}$ ranged from 0.618 to 0.869 in the normal populations while values ranged from 0.556 to 0.805 in the bottlenecked ones. Mean values tended to be lower for the bottlenecked lines than the normal lines (Figure 2), with a significant overall treatment effect $\left[F_{(1,32)}=21.98, p<0.001\right]$. There was again no significant source-population effect (Wald $p$ $=0.794$ ). Microsatellite allele frequencies are shown in Online Resource 2 in Supplementary Material.

\section{Response to Selection, as a Function of Generation Number}

Prior to selection, the temperature at death (TAD) of our least killifish populations averaged $39.24^{\circ} \mathrm{C}$ (with an S.E. of $0.03^{\circ} \mathrm{C}$ ). There was a significant increase in heat tolerance for each of the three selection lines established with fish from the normal populations, but for only one of the three selection lines established from the bottlenecked populations (Figure 3). The lack of response was especially obvious for the Lake Martin bottlenecked population (Figure 3C). For all selection lines combined, the cumulative response averaged $0.027^{\circ} \mathrm{C}$ per generation, for a total of about $0.1^{\circ} \mathrm{C}$ over the four generations.

\section{Response to Selection as a Function of Cumulative Selection Intensity}

For the three source populations combined, the selection response increased significantly as a function of the cumulative selection intensity $\left[F_{(1,14)}=53.0, p<0.001\right.$, and $F_{(1,14)}=$ 10.9, $p=0.005$ for respectively the normal and bottlenecked lines; Figure 4). For such regressions, the regression coefficient is a direct estimate of the realized heritability, resulting in

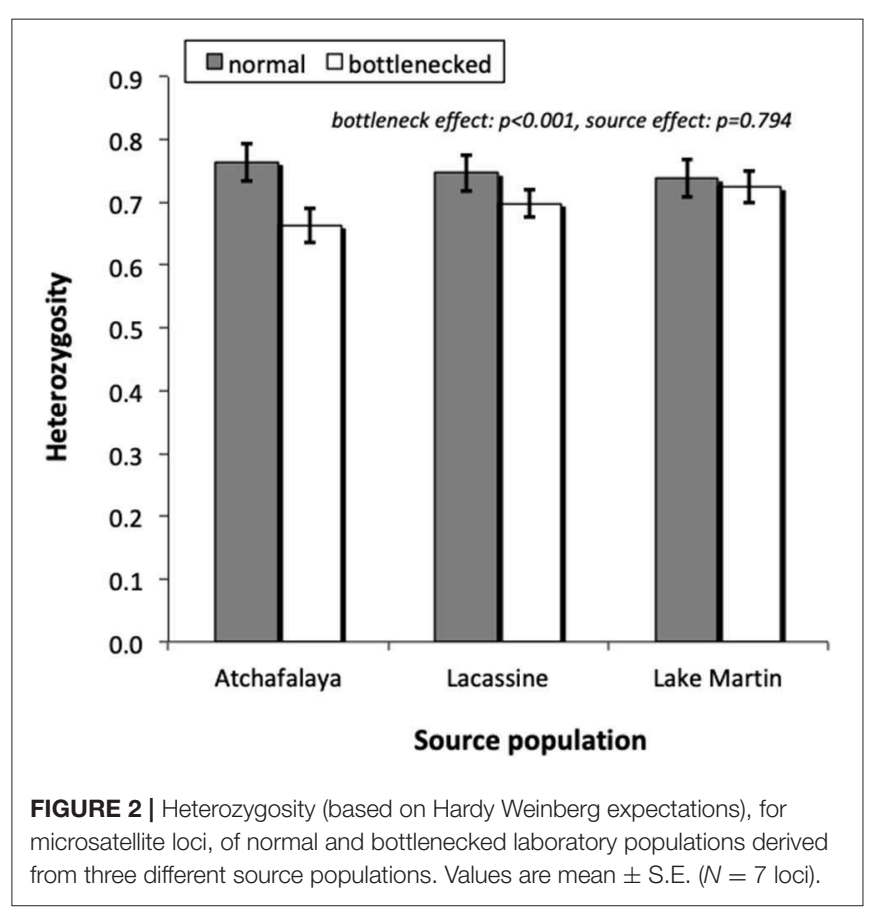




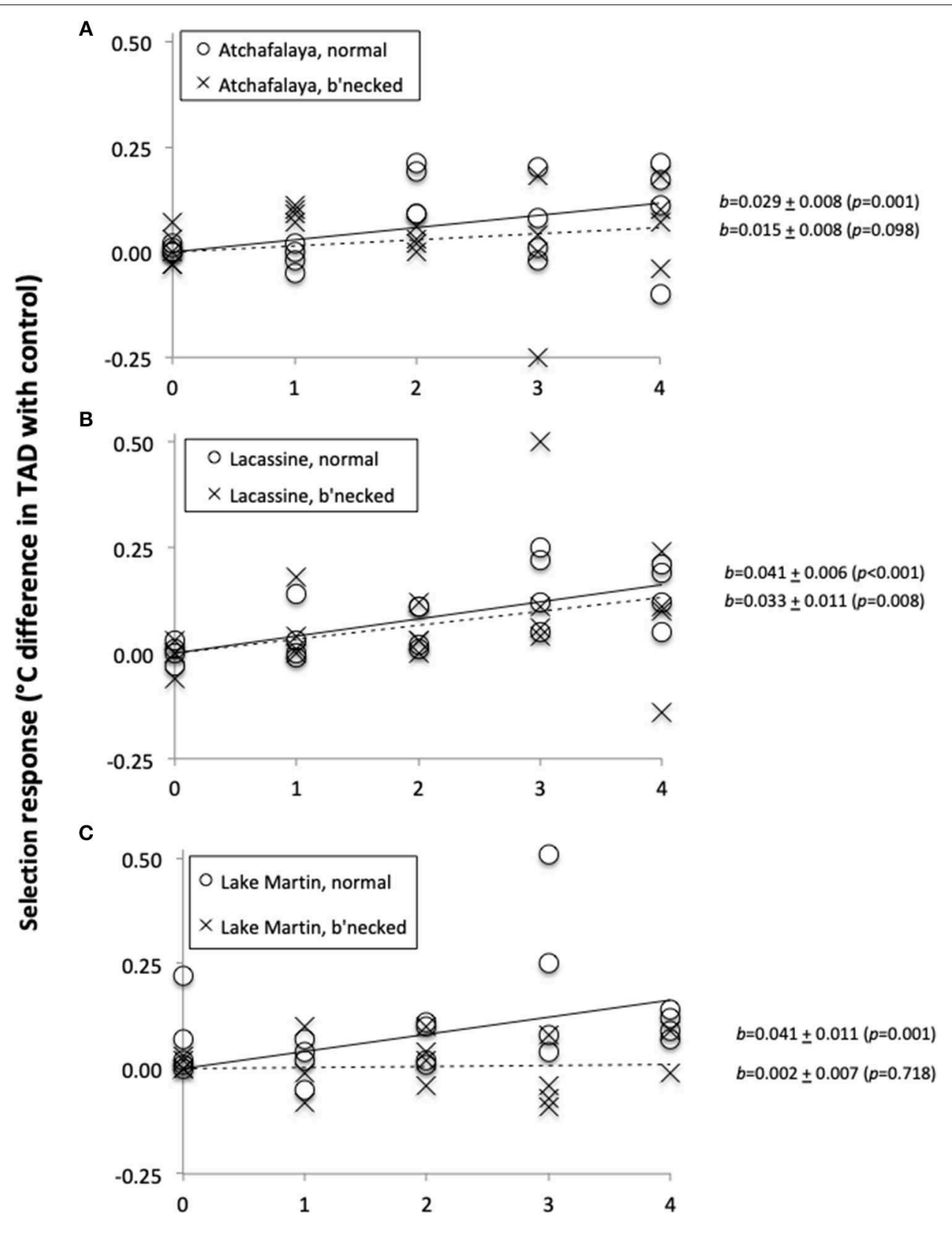

Generation

FIGURE 3 | Selection response (difference in temperature-at-death (TAD) between fish from a selection line and fish of its paired control line), as a function of generation number. Fish were from three source populations: Atchafalaya (A), Lacassine (B), and Lake Martin (C). Open circles and solid regression lines represent normal populations, while crosses and broken regression lines represent bottlenecked populations.

realized heritability estimates of $0.224 \pm 0.031$ and 0.106 \pm 0.032 for the normal and bottlenecked lines respectively. For all lines combined, the realized heritability estimate was $0.165 \pm 0.024$. When considering the selection response for each source population separately, regressions were statistically significant $(p<0.05)$ for all three normal lines and for one of the three bottlenecked lines (Online Resource 3 in Supplementary Material).
The response can also be standardized in relative terms as is done for the concept of evolvability $\left(R /\left(^{*} m\right)\right.$ where $R$ is the response to selection, $i$ is the selection intensity and $m$ is the population mean prior to selection (Roff, 1997). Doing this for the responses observed for each generation in the selection experiment yields an average response, per generation of selection, of $0.05 \%$ for the normal lines and $0.03 \%$ for the bottlenecked lines. Assuming that such a response would stay 


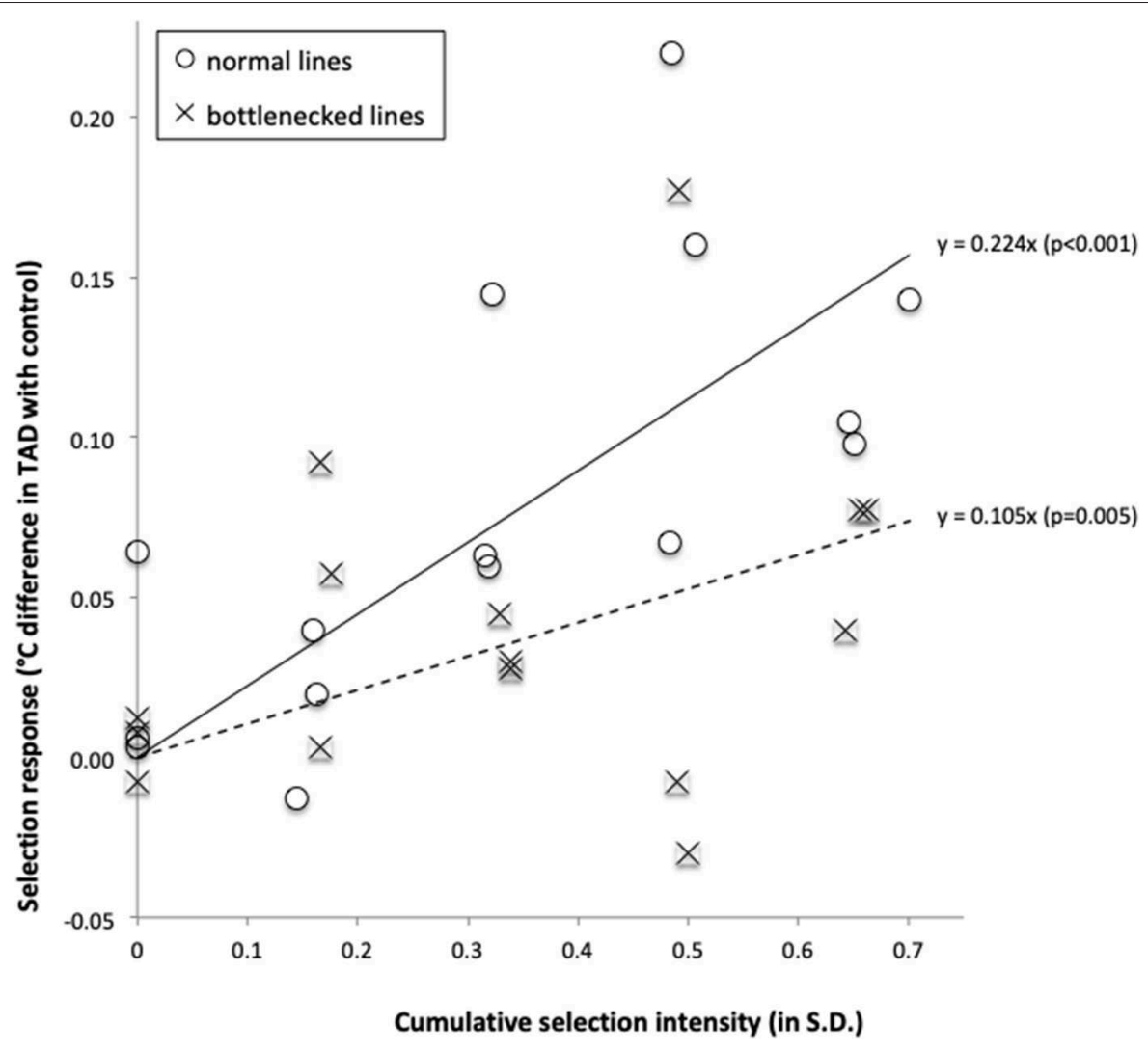

FIGURE 4 | Selection response (difference in temperature-at-death (TAD) between fish from a selection line and fish of its paired control line), as a function of the cumulative selection intensity. Data were grouped by source population type: normal populations (open circles, solid regression line) and bottlenecked populations (crosses, broken regression line).

constant, these evolvability numbers equate to an average of about 25 generations of selection for a total response of $1 \%$.

\section{DISCUSSION}

The present study used a laboratory-selection approach, with normal and bottlenecked populations of a fish species with a short generation time, to gain insights into the potential for evolutionary rescue from heat stress. To our knowledge, this is the first such study for a vertebrate species. The study's findings demonstrate that such an experimental approach can be used to provide insights into an evolutionary response to climate change.

The single but severe bottleneck used in the present study resulted in a loss of genetic variation for a set of microsatellite markers. Compared to control populations, bottlenecked populations had, on average, a $7 \%$ lower heterozygosity and $13 \%$ fewer alleles. Bottlenecked populations had 3-6 alleles at the seven loci analyzed although the maximum in populations founded with two fish is 4 alleles. This shows that replacing males shortly after the start of the bottlenecked populations caused the actual number of founders to be three rather than two. Associations between population bottlenecks and lowered genetic diversity have been observed in various taxa
(O'Leary et al., 2014; Segelbacher et al., 2014; Xue et al., 2015). A meta-analysis also detected reduced allelic richness and heterozygosity in fish populations that experienced bottlenecks through overfishing (Pinsky and Palumbi, 2014). The population bottlenecks also affected trait means for heat tolerance in our populations. An earlier study on two of the three laboratory populations used in the present study (and assayed prior to the start of the selection process) did detect evidence of inbreeding depression. These bottlenecked laboratory populations had heat tolerances (quantified as in the present study) that were on average lower by $0.11^{\circ} \mathrm{C}$ (Doyle et al., 2011).

Our selection for an increased temperature-at-death (TAD) resulted in a significant response; TAD increased by an average of about $0.1{ }^{\circ} \mathrm{C}$ over the four generations of selection. This response to selection is consistent with the average heritability of 0.20 detected in the same populations before the start of the selection process (Doyle et al., 2011) and confirms that these populations have the potential for adapting to elevated water temperatures. This contrasts with an earlier study with $H$. formosa from Florida and South Carolina source populations, where artificial selection for heat tolerance did not result in a clear response (Baer and Travis, 2000). Compared to the present study, the Baer and Travis study's methodology differed in several important aspects. The latter used a different selection 
criterion (cessation of gill movement rather than survival), selected on multiple age classes (juveniles and adults), was limited to three generations, and suffered from loss of some laboratory lines (Baer and Travis, 2000). These differences may explain the discrepancy in study outcomes, though it is also possible that results differed due to genetic differences among source populations. An indication of among-population variability in the potential for adaptation to heat stress was seen in the closelyrelated poeciliid Gambusia holbrooki. Meffe et al. (1995) reported both a heritability estimate of 0.32 for TAD and an elevated heat tolerance in fish from a South Carolina pond that had for 30 years (albeit intermittently) received heated effluents from a nuclear reactor. In contrast, a study comparing heat tolerance among G. holbrooki from Florida sites that differed in thermal regimes, did not detect evidence of adaptation to elevated water temperatures (Klerks and Blaha, 2009). While other studies did not find evidence that a response to selection for heat tolerance differs among populations (e.g., Magiafoglou and Hoffmann, 2003), among-population variability is likely to vary widely.

The present study's bottlenecked lines did, as a whole, respond to selection for an increased heat tolerance, but the response was slower (by about 50\%) than it was for the normal lines. As indicated by reduced genetic variation at microsatellite loci, this reduction in response could be attributed to the bottlenecked lines having reduced genetic variation for traits underlying heat tolerance. A bottleneck of three fish can result in a large decrease in genetic variability. However, the present study's bottleneck populations were allowed to rapidly increase in size following the initial bottleneck, limiting the loss of variability (Nei et al., 1975). The theoretically-expected initial decrease in genetic variation by $1 / 6$ th ( 1 divided by $2 \mathrm{Ne}$ ) would have been followed by just small decreases in subsequent generations. The actual effect of bottlenecks appears to be highly variable (Bouzat, 2010), in line with the contrast in selection response between our Lake Martin and Lacassine bottlenecked populations. While a bottleneck will typically result in a decrease in additive genetic variation $\left(\mathrm{V}_{\mathrm{A}}\right)$ for a trait controlled by genes that act additively (Falconer and Mackay, 1996), an increase in $\mathrm{V}_{\mathrm{A}}$ becomes more likely when dominance and epistatic effects are important (Wang et al., 1998; Naciri-Graven and Goudet, 2003). An increase in $V_{A}$ has been reported in various studies (including Bryant and Meffert, 1995; Van Heerwaarden et al., 2008), though the lack of a faster selection response in the bottlenecked lines argues against an increased $\mathrm{V}_{\mathrm{A}}$ in the present study. A quantification of the narrow-sense heritabilities $\left(\mathrm{V}_{\mathrm{A}}\right.$ divided by the total phenotypic variance) for heat tolerance in two of the three sets of $H$. formosa populations selected in the present study did find lower heritabilities in the bottlenecked lines than in the normal ones (Doyle et al., 2011), indicating a reduction in $\mathrm{V}_{\mathrm{A}}$. The heritability estimates obtained in the latter study averaged 0.230 and 0.168 for the normal and bottlenecked lines respectively-estimates that were close to the realized heritability estimates ( 0.224 for normal lines, 0.106 for bottlenecked lines) obtained from the selection responses reported here.

The present study treats heat tolerance as a quantitative trait, so provides no direct insights into the specific genes or specific physiological mechanisms underlying the temporal changes in heat tolerance. Differences in heat tolerance may be largely determined by changes in a small number of specific genes such as the heat shock proteins (HSPs) (Sanders et al., 1991; Bettencourt et al., 1999), and heritable variation for HSP expression has been reported for populations of sea turtles (Tedeschi et al., 2016). However, temperature affects a wide variety of physiological and biochemical processes, such that differences in heat tolerance could be related to a variety of genetic changes. Research on coral populations differing in heat tolerance has provided evidence for the involvement of many genes and indicated that increased heat tolerance may be a consequence of an elevated constitutive expression of these genes (Barshis et al., 2013). The polygenic nature of temperature tolerance has also been demonstrated at the species-level in conifers (Yeaman et al., 2016) and at the population-level in anoles (Campbell-Staton et al., 2017).

The results from the least killifish selection experiment demonstrate that, under specific conditions, some populations may be able to adapt to the increase in temperatures associated with climate change. The response was about $0.1^{\circ} \mathrm{C}$ in 4 generations of intense selection, corresponding to an evolvability of about $0.05 \%$ per generation or $1 \%$ in 20 generations) indicating that the ability to keep up with increasing temperatures from climate change may be limited to organisms with a short generation time-as global temperatures have increased at a rate of about $0.15^{\circ} \mathrm{C} /$ decade and future increases may exceed this rate (IPCC, 2014). Results for the selection experiment with the bottlenecked population also demonstrate that the response may be much slower for populations that have gone through a population bottleneck. Our earlier research with $H$. formosa also showed that bottlenecked populations may be at a disadvantage with respect to dealing with heat stress as a consequence of inbreeding depression (Doyle et al., 2011).

The least killifish populations responded to laboratory selection for an increased temperature-at-death when water temperatures increased at $2^{\circ} \mathrm{C} /$ day. This rate is much higher than that of temperature increase under ongoing climate change. However, climate change will result in an increased frequency and longer duration of heat waves (IPCC, 2014) and organisms' upper thermal limit may well be approached at a rate of $2^{\circ} \mathrm{C} /$ day during such events. The selection pressure that was applied here was for one specific trait (tolerance to a lethal temperature) associated with increasing water temperature. However, stressors other than high temperature are associated with climate change, and adaptation to climate change may involve not just genes associated with stress tolerance but also behavioral ones (Bay et al., 2018). In addition, climate change may affect other species that the focal species may depend on. For example, effects via species interactions such as loss of a food source are likely to be important contributors to extinctions (Cahill et al., 2013). We currently do not know what the most critical effects are with respect to population survival at higher temperatures in most of the at-risk species.

Although our results indicate that natural populations may possibly respond to selection imposed by a warming climate, the response was observed for a specific laboratory environment and over a limited number of generations. Theoretical considerations 
predict that the response to selection depends on the specific environmental conditions and will decrease over time (Falconer and Mackay, 1996). It is not clear how important these theoretical limitations are. In green anoles, short-term changes in cold tolerance within a population were consistent with observed population-differentiation along a spatial gradient (CampbellStaton et al., 2017). In mosquitofish, laboratory-quantified heritability was consistent with differentiation for heat tolerance observed among wild populations (Meffe et al., 1995). Similarly, while genetic variances and covariances underlying a trait may change over time, a study addressing this directly in the context of climate change did not detect such changes (Garant et al., 2008). The challenges posed by the laboratory to field and the short-term to long-term extrapolations and the lack of insight into the many relevant genetic, demographic and biological processes that affect the evolutionary responses to climate change led to a recent conclusion that it is still unclear to what extent evolutionary changes in response to climate will contribute to species' persistence (Grant, 2017). The geological record indicates that several biotic turnovers appear to have coincided with episodes of rapid climate change (Crowley and North, 1988) indicative of limits to the potential for successful adaptation to climate change.

\section{ETHICS STATEMENT}

The care and use of the fish was in compliance with all relevant local animal welfare laws, guidelines and policies. Animal Use Protocols were approved by the University of Louisiana at

\section{REFERENCES}

Aitken, S. N., Yeaman, S., Holliday, J. A., Wang, T., and Curtis-McLane, S. (2008). Adaptation, migration or extirpation: climate change outcomes for tree populations. Evol. Appl. 1, 95-111. doi: 10.1111/j.1752-4571.2007.00013.x

Athrey, N. R. G., Leberg, P. L., and Klerks, P. L. (2007). Laboratory culturing and selection for increased resistance to cadmium reduce genetic variation in the least killifish, Heterandria formosa. Environ. Toxicol. Chem. 26, 1916-1921. doi: 10.1897/06-589R.1

Baer, C. F., and Travis, J. (2000). Direct and correlated responses to artificial selection on acute thermal stress tolerance in a live-bearing fish. Evolution 54, 238-244. doi: 10.1111/j.0014-3820.2000.tb00024.x

Barshis, D. J., Ladner, J. T., Oliver, T. A., Seneca, F. O., Traylor-Knowles, N., and Palumbi, S. R. (2013). Genomic basis for coral resilience to climate change. Proc. Natl. Acad. Sci. U.S.A. 110, 1387-1392. doi: 10.1073/pnas. 1210224110

Bay, R. A., Harrigan, R. J., Underwood, V. L., Gibbs, H. L., Smith, T. B., and Ruegg, K. (2018). Genomic signals of selection predict climate-driven population declines in a migratory bird. Science 359, 83-86. doi: 10.1126/science.aan4380

Beever, E. A., Ray, C., Mote, P. W., and Wilkening, J. L. (2010). Testing alternative models of climate-mediated extirpations. Ecol. Appl. 20, 164-178. doi: 10.1890/08-1011.1

Bell, G., and Collins, S. (2008). Adaptation, extinction and global change. Evol. Appl. 1, 3-16. doi: 10.1111/j.1752-4571.2007.00011.x

Bennett, A. F., Dao, K. M., and Lenski, R. E. (1990). Rapid evolution in response to high-temperature selection. Nature 346, 79-81. doi: 10.1038/346079a0

Bettencourt, B. R., Feder, M. E., and Cavicchi, S. (1999). Experimental evolution of hsp70 expression and thermotolerance in Drosophila melanogaster. Evolution 53, 484-492. doi: 10.1111/j.1558-5646.1999.tb03783.x

Bouzat, J. L. (2010). Conservation genetics of population bottlenecks: the role of chance, selection, and history. Conser. Genetics 11, 463-478. doi: $10.1007 /$ s10592-010-0049-0
Lafayette's Animal Care and Use Committee (approvals 20048701-071 and 2006-8717-057).

\section{AUTHOR CONTRIBUTIONS}

PK was involved in obtaining funding, designing the research, conducting the research, analyzing the data, and preparing the manuscript. PL was involved in obtaining funding, designing the research, and preparing the manuscript. GA was involved in conducting the research, analyzing the microsatellite data, and preparing the manuscript.

\section{ACKNOWLEDGMENTS}

We thank Margo Blaha and Cathy Doyle for assistance with collection and maintenance of fish populations and the University of Louisiana at Lafayette's Ecology Center for logistical support. This research was funded by the United States Environmental Protection Agency through grant R-829420010 to the Louisiana Board of Regents. This paper has not been subjected to the EPA's peer and policy review process and therefore does not necessarily reflect the views of the Agency and no official endorsement should be inferred.

\section{SUPPLEMENTARY MATERIAL}

The Supplementary Material for this article can be found online at: https://www.frontiersin.org/articles/10.3389/fevo. 2019.00270/full\#supplementary-material

Bryant, E. H., and Meffert, L. M. (1995). An analysis of selectional response in relation to a population bottleneck. Evolution 49, 626-634. doi: 10.1111/j.1558-5646.1995.tb02299.x

Bürger, R., and Lynch, M. (1995). Evolution and extinction in a changing environment: a quantitative-genetic analysis. Evolution 49, 151-163. doi: 10.1111/j.1558-5646.1995.tb05967.x

Cahill, A. E., Aiello-Lammens, M. E., Fisher-Reid, M. C., Hua, X., Karanewsky, C. J., Yeong Ryu, H., et al. (2013). How does climate change cause extinction? Proc. R. Soc. B Biol. Sci. 280:20121890. doi: 10.1098/rspb. 2012.1890

Campbell-Staton, S. C., Cheviron, Z. A., Rochette, N., Catchen, J., Losos, J. B., and Edwards, S. V. (2017). Winter storms drive rapid phenotypic, regulatory, and genomic shifts in the green anole lizard. Science 357, 495-498. doi: 10.1126/science.aam5512

Carlson, S. M., Cunningham, C. J., and Westley, P. A. H. (2014). Evolutionary rescue in a changing world. Trends Ecol. Evol. 29, 521-530. doi: 10.1016/j.tree.2014.06.005

Coats, R., Perez-Losada, J., Schladow, G., Richards, R., and Goldman, C. (2006). The warming of Lake Tahoe. Climatic Change 76, 121-148. doi: 10.1007/s10584-005-9006-1

Comte, L., Buisson, L., Daufresne, M., and Grenouillet, G. (2013). Climate-induced changes in the distribution of freshwater fish: observed and predicted trends. Freshwater Biol. 58, 625-639. doi: 10.1111/fwb.12081

Crowley, T. J., and North, G. R. (1988). Abrupt climate change and extinction events in earth history. Science 240, 996-1002. doi: $10.1126 /$ science. 240.4855 .996

Diamond, S. A., Oris, J. T., and Guttman, S. I. (1995). Adaptation to fluoranthene exposure in a laboratory population of fathead minnows. Environ. Toxicol. Chem. 14, 1393-1400. doi: 10.1002/etc.5620140816

Dokulil, M. T. (2013). Impact of climate warming on European inland waters. Inland Waters 4, 27-40. doi: 10.5268/IW-4.1.705 
Doyle, C. M., Leberg, P. L., and Klerks, P. L. (2011). Heritability of heat tolerance in a small livebearing fish, Heterandria formosa. Ecotoxicology 20, 535-542. doi: 10.1007/s10646-011-0624-2

Falconer, D. S., and Mackay, T. F. C. (1996). Introduction to Quantitative Genetics. Essex: Longman.

Garant, D., Hadfield, J. D., Kruuk, L. E. B., and Sheldon, B. C. (2008). Stability of genetic variance and covariance for reproductive characters in the face of climate change in a wild bird population. Mol. Ecol. 17, 179-188. doi: 10.1111/j.1365-294X.2007.03436.x

Grant, P. R. (2017). Evolution, climate change, and extreme events. Science 357, 451-452. doi: 10.1126/science.aao2067

Hoffmann, A. A., and Blows, M. W. (1993). "Evolutionary genetics and climate change: will animals adapt to global warming?"” in Biotic Interactions and Global Change, eds. P.M. Kareiva, J.G. Kingsolver \& R.B. Huey. (Sunderland, MA: Sinauer Associates), 165-178.

IPCC (2014). "Climate Change 2014: Synthesis Report," in Contribution of Working Groups I, II and III to the Fifth Assessment Report of the Intergovernmental Panel on Climate Change, (Geneva: IPCC).

Isaak, D. J., Wollrab, S., Horan, D., and Chandler, G. (2012). Climate change effects on stream and river temperatures across the northwest U.S. from 1980-2009 and implications for salmonid fishes. Climatic Change 113, 499-524. doi: 10.1007/s10584-011-0326-Z

Izzo, C., Doubleday, Z. A., Grammer, G. L., Gilmore, K. L., Alleway, H. K., Barnes, T. C., et al. (2016). Fish as proxies of ecological and environmental change. Rev. Fish Biol. Fish. 26, 265-286. doi: 10.1007/s11160-016-9424-3

Jeppesen, E., Mehner, T., Winfield, I. J., Kangur, K., Sarvala, J., Gerdeaux, D., et al. (2012). Impacts of climate warming on the long-term dynamics of key fish species in 24 European lakes. Hydrobiologia 694, 1-39. doi: 10.1007/s10750-012-1182-1

Kavanagh, K. D., Haugen, T. O., Gregersen, T., Jernvall, J., and Vøllestad, L. A. (2010). Contemporary temperature-driven divergence in a Nordic freshwater fish under conditions commonly thought to hinder adaptation. BMC Evol. Biol. 10:350. doi: 10.1186/1471-2148-10-350

Kelly, M. W., DeBiasse, M. B., Villela, V. A., Roberts, H. L., and Cecola, C. F. (2016). Adaptation to climate change: trade-offs among responses to multiple stressors in an intertidal crustacean. Evol. Appl. 9, 1147-1155. doi: 10.1111/eva.12394

Klerks, P. L., and Blaha, M. A. (2009). Heat tolerance as an indicator of climate change impacts: general considerations and a case study in poeciliid fish. Environ. Bioindicators 4, 46-66. doi: 10.1080/15555270902729280

Klerks, P. L., and Levinton, J. S. (1989). Rapid evolution of metal resistance in a benthic oligochaete inhabiting a metal-polluted site. Biol. Bull. 176, 135-141. doi: $10.2307 / 1541580$

Klerks, P. L., Xie, L., and Levinton, J. S. (2011). Quantitative genetics approaches to study evolutionary processes in ecotoxicology; a perspective from research on the evolution of resistance. Ecotoxicology 20, 513-523. doi: 10.1007/s10646-011-0640-2

Kovach, R. P., Gharrett, A. J., and Tallmon, D. A. (2012). Genetic change for earlier migration timing in a pink salmon population. Proc. R. Soc. B Biol. Sci. 279, 3870-3878. doi: 10.1098/rspb.2012.1158

Kraemer, B. M., Hook, S., Huttula, T., Kotilainen, P., O’Reilly, C. M., Peltonen, A., et al. (2015). Century-long warming trends in the upper water column of Lake Tanganyika. PLoS ONE 10:e0132490. doi: 10.1371/journal.pone.0132490

Leips, J., and Travis, J. (1999). The comparative expression of life-history traits and its relationship to the numerical dynamics of four populations of the least killifish. J. Anim. Ecol. 68, 595-616. doi: 10.1046/j.1365-2656.1999.00311.x

Lewis, P. O., and Zaykin, D. (2001). GDA (Genetic Data Analysis): Computer Program for the Analysis of Allelic Data. Version 1.1 ed. (Storrs, CT: University of Connecticut).

Lynch, A. J., Myers, B. J. E., Chu, C., Eby, L. A., Falke, J. A., Kovach, R. P., et al. (2016). Climate change effects on North American inland fish populations and assemblages. Fisheries 41, 346-361. doi: 10.1080/03632415.2016. 1186016

Magiafoglou, A., and Hoffmann, A. A. (2003). Thermal adaptation in Drosophila serrata under conditions linked to its southern border: unexpected patterns from laboratory selection suggest limited evolutionary potential. J. Genetics 82, 179-189. doi: 10.1007/BF02715817

McClanahan, T. R. (2004). The relationship between bleaching and mortality of common corals. Marine Biol. 144, 1239-1245. doi: 10.1007/s00227-003-1271-9
Meffe, G. K., Weeks, S. C., Mulvey, M., and Kandl, K. L. (1995). Genetic differences in thermal tolerance of eastern mosquitofish (Gambusia holbrooki; Poeciliidae) from ambient and thermal ponds. Can. J. Fish. Aquatic Sci. 52, 2704-2711. doi: 10.1139/f95-259

Naciri-Graven, Y., and Goudet, J. (2003). The additive genetic variance after bottlenecks is affected by the number of loci involved in epistatic interactions. Evolution 57, 706-716. doi: 10.1111/j.0014-3820.2003.tb00284.x

Nei, M., Maruyama, T., and Chakraborty, R. (1975). The bottleneck effect and genetic variability in populations. Evolution 29, 1-10. doi: 10.1111/j.1558-5646.1975.tb00807.x

O’Leary, S. J., Dunton, K. J., King, T. L., Frisk, M. G., and Chapman, D. D. (2014). Genetic diversity and effective size of Atlantic sturgeon, Acipenser oxyrhinchus oxyrhinchus river spawning populations estimated from the microsatellite genotypes of marine-captured juveniles. Conser. Genetics 15, 1173-1181. doi: 10.1007/s10592-014-0609-9

O’Reilly, C. M., Sharma, S., Gray, D. K., Hampton, S. E., Read, J. S., Rowley, R. J., et al. (2015). Rapid and highly variable warming of lake surface waters around the globe. Geophys. Res. Lett. 42:2015GL066235. doi: 10.1002/2015GL 066235

Oziolor, E. M., Bigorgne, E., Aguilar, L., Usenko, S., and Matson, C. W. (2014). Evolved resistance to $\mathrm{PCB}$ - and $\mathrm{PAH}$-induced cardiac teratogenesis, and reduced CYP1A activity in Gulf killifish (Fundulus grandis) populations from the Houston Ship Channel, Texas. Aquatic Toxicol. 150, 210-219. doi: 10.1016/j.aquatox.2014.03.012

Perrier, C., Ferchaud, A.-L., Sirois, P., Thibault, I., and Bernatchez, l. (2017). Do genetic drift and accumulation of deleterious mutations preclude adaptation? Empirical investigation using RADseq in a northern lacustrine fish. Mol. Ecol. 26, 6317-6335. doi: 10.1111/mec.14361

Pinsky, M. L., and Palumbi, S. R. (2014). Meta-analysis reveals lower genetic diversity in overfished populations. Mol. Ecol. 23, 29-39. doi: 10.1111/mec.12509

Réale, D., McAdam, A. G., Boutin, S., and Berteaux, D. (2003). Genetic and plastic responses of a northern mammal to climate change. Proc. $R$ Soc. London Series B 270, 591-596. doi: 10.1098/rspb.2002.2224

Reid, N. M., Proestou, D. A., Clark, B. W., Warren, W. C., Colbourne, J. K., Shaw, J. R., et al. (2016). The genomic landscape of rapid repeated evolutionary adaptation to toxic pollution in wild fish. Science 354, 1305-1308. doi: $10.1126 /$ science.aah4993

Reusch, T. B. H., and Wood, T. E. (2007). Molecular ecology of global change. Mol. Ecology 16, 3973-3992. doi: 10.1111/j.1365-294X.2007.03454.x

Roff, D. A. (1997). Evolutionary Quantitative Genetics. New York, NY: Chapman \& Hall.

Sanders, B. M., Hope, C., Pascoe, V. M., and Martin, L. S. (1991). Characterization of the stress protein response in two species of Collisella limpets with different temperature tolerances. Physiol. Zool. 64, 1471-1489. doi: 10.1086/physzool.64.6.30158225

Schmid, M., Hunziker, S., and Wüest, A. (2014). Lake surface temperatures in a changing climate: a global sensitivity analysis. Climatic Change 124, 301-315. doi: 10.1007/s10584-014-1087-2

Segelbacher, G., Strand, T. M., Quintela, M., Axelsson, T., Jansman, H. A. H., Koelewijn, H. P., et al. (2014). Analyses of historical and current populations of black grouse in central Europe reveal strong effects of genetic drift and loss of genetic diversity. Conser. Genetics 15, 1183-1195. doi: 10.1007/s10592-014-0610-3

Sheldon, B. C., Kruuk, L. E. B., and Meril,ä, J. (2003). Natural selection and inheritance of breeding time and clutch size in the collared flycatcher. Evolution 57, 406-420. doi: 10.1111/j.0014-3820.2003.tb00274.x

Sinervo, B., Méndez-de-la-Cruz, F., Miles, D. B., Heulin, B., Bastiaans, E., Villagrán-Santa Cruz, M., et al. (2010). Erosion of lizard diversity by climate change and altered thermal niches. Science 328, 894-899. doi: $10.1126 /$ science. 1184695

Skelly, D. K., Joseph, L. N., Possingham, H. P., Freidenburg, L. K., Farrugia, T. J., Kinnison, M. T., et al. (2007). Evolutionary responses to climate change. Conser. Biol. 21, 1353-1355. doi: 10.1111/j.1523-1739.2007.00764.x

Tedeschi, J. N., Kennington, W. J., Tomkins, J. L., Berry, O., Whiting, S., Meekan, M. G., et al. (2016). Heritable variation in heat shock gene expression: a potential mechanism for adaptation to thermal stress in embryos of sea turtles. Proc. R. Soc. B Biol. Sci. 283:1822. doi: 10.1098/rspb.2015.2320 
Thomas, C. D., Cameron, A., Green, R. E., Bakkenes, M., Beaumont, L. J., Collingham, Y. C., et al. (2004). Extinction risk from climate change. Nature 427, 145-148. doi: 10.1038/nature02121

Van Heerwaarden, B., Willi, Y., Kristensen, T. N., and Hoffmann, A. A. (2008). Population bottlenecks increase additive genetic variance but do not break a selection limit in rain forest Drosophila. Genetics 179, 2135-2146. doi: 10.1534/genetics.107.082768

Wang, J., Caballero, A., Keightley, P. D., and Hill, W. G. (1998). Bottleneck effect on genetic variance: a theoretical investigation of the role of dominance. Genetics 150, 435-447.

Weigensberg, I., and Roff, D. A. (1996). Natural heritabilities: can they be reliably estimated in the laboratory? Evolution 50, 2149-2157. doi: 10.1111/j.1558-5646.1996.tb03605.x

Xie, L., and Klerks, P. L. (2003). Responses to selection for cadmium resistance in the least killifish, Heterandria formosa. Environ. Toxicol. Chem. 22, 313-320. doi: $10.1002 /$ etc.5620220211

Xie, L., and Klerks, P. L. (2004). Fitness costs of resistance to cadmium in the least killifish (Heterandria formosa). Environ. Toxicol. Chem. 23, 1499-1503. doi: 10.1897/03-96
Xue, Y., Prado-Martinez, J., Sudmant, P. H., Narasimhan, V., Ayub, Q. Szpak, M., et al. (2015). Mountain gorilla genomes reveal the impact of long-term population decline and inbreeding. Science 348, 242-245. doi: 10.1126/science.aaa3952

Yeaman, S., Hodgins, K. A., Lotterhos, K. E., Suren, H., Nadeau, S., Degner, J. C., et al. (2016). Convergent local adaptation to climate in distantly related conifers. Science 353, 1431-1433. doi: 10.1126/science.aaf7812

Conflict of Interest Statement: The authors declare that the research was conducted in the absence of any commercial or financial relationships that could be construed as a potential conflict of interest.

Copyright (c) 2019 Klerks, Athrey and Leberg. This is an open-access article distributed under the terms of the Creative Commons Attribution License (CC BY). The use, distribution or reproduction in other forums is permitted, provided the original author(s) and the copyright owner(s) are credited and that the original publication in this journal is cited, in accordance with accepted academic practice. No use, distribution or reproduction is permitted which does not comply with these terms. 